\title{
Influence of test procedure on dielectric breakdown strength of alumina
}

\author{
Bjoern MIELLER ${ }^{*}$ \\ Bundesanstalt fuer Materialforschung und -pruefung (BAM), \\ Division Advanced Technical Ceramics, 12200 Berlin, Germany \\ Received: September 20, 2018; Revised: December 3, 2018; Accepted: December 5, 2018 \\ (c) The Author(s) 2019.

\begin{abstract}
Dielectric strength testing of ceramics can be performed with various setups and parameters. Comparisons of results from different sources are often not meaningful, because the results are strongly dependent on the actual testing procedure. The aim of this study is to quantify the influence of voltage ramp rate, electrode size, electrode conditioning, and sample thickness on the measured AC dielectric strength of a commercial alumina. Mean values, Weibull moduli, and failure probabilities determined in standardized short time tests are evaluated and related to withstand voltage tests. Dielectric strength values in the range from 21.6 to $33.2 \mathrm{kV} \cdot \mathrm{mm}^{-1}$ were obtained for the same material using different testing procedures. Short time tests resulted in small standard deviations $\left(<2 \mathrm{kV} \cdot \mathrm{mm}^{-1}\right)$ and high Weibull moduli around 30, while withstand tests at voltage levels with low and virtual zero failure probability in short time tests resulted in large scatter of withstand time and Weibull moduli $<1$. The strong decrease in Weibull moduli is attributed to progressive damage from partial discharge and depolarization during AC testing. These findings emphasize the necessity of a thorough documentation of testing procedure and highlight the importance of withstand voltage tests for a comprehensive material characterization.
\end{abstract}

Keywords: dielectric strength; dielectric breakdown; withstand voltage test; high AC voltage testing

\section{Introduction}

Dielectric breakdown is a critical failure mode in many electroceramic applications. Especially ceramic insulators, but also piezoceramics, and dielectrics for pulsed power applications must withstand a certain electric field. The characteristic value to quantify this material property is dielectric breakdown strength, or just dielectric strength. Per definition, dielectric strength is the voltage gradient at which dielectric failure of an

* Corresponding author.

E-mail: bjoern.mieller@bam.de insulating material occurs under specific conditions of test. The nature of dielectric failure of ceramics is being studied since several decades [1]. It is widely accepted that dielectric breakdown of ceramics is a combination of thermal, mechanical, and electronic contributions [2]. Many years ago, Kishimito et al. [3,4] correlated dielectric strength to mechanical properties and surface properties. They discussed that surface flaws play an important role in both mechanical and dielectric failure and therefore, at least in thick specimen, correlations in the Weibull distributions are found. In contrast, Young et al. [5] showed that there is not a simple correlation between mechanical and 
dielectric failure in high voltage multilayer ceramic capacitors. Different mechanisms and origins of failure were observed in that study.

Dielectric strength has also been related to fracture toughness and wear [6,7]. Higher purity and $\mathrm{ZrO}_{2}$ doping enhanced both fracture toughness and dielectric strength in alumina [6]. Haddour et al. [7] discussed that mechanical and dielectric phenomena are effective in debris formation during wear. They concluded that high breakdown strength generally involves weak wear, although their data does not invariably follow this tendency. A proportionality of dielectric strength to the -0.5 power of relative permittivity is shown by different groups of researchers [8,9]. Trapping of charges $[10,11]$ and space charge limited conductivity [12-14] are recently discussed to be decisive for breakdown channel formation in ceramics.

A noteworthy characteristic of dielectric strength, especially with respect to test conditions, is its thickness dependence. In contrast to common mechanical strength concepts, dielectric strength shows a $1 / \sqrt{d}$ dependence, where $d$ is the sample thickness $[6,8,15]$. Neusel and Schneider [15] concluded that the thickness dependence cannot be explained by the Weibull concept. They proposed a concept of conducting filaments that initiate breakdown, with the minimum length of such filaments being the reason for a thickness independent intrinsic breakdown and a thickness dependent extrinsic breakdown. Fischer and Schneider [16] experimentally determined the filament length in a commercial borosilicate glass to be around $20 \mu \mathrm{m}$.

Besides these fundamental studies on the nature of dielectric breakdown, several groups work on new materials with enhanced dielectric strength for insulation $[17,18]$ or energy storage in pulsed-power circuits [19-22]. Although dielectric strength testing often is a key feature of the publications in this field, testing procedures are strongly different and in many cases poorly described. With this study, we would like to address this issue. If a ceramic material is supposed to be characterized with respect to its dielectric strength for a practical application, many choices have to be made regarding sample properties and test procedure. The ASTM D149 [23] provides a decent basis for choosing or developing an appropriate test design. But there are important criteria of a dielectric strength test which are not unambiguously prescribed by the standard, including voltage ramp rate and electrode size and condition.
The aim of this study is to quantify the effect of different testing conditions, all within the framework of the valid standard, on the dielectric strength results for a commercial alumina. Furthermore, we discuss the relevance of well-established short time tests and the failure probabilities which can be derived from these tests with respect to the durability of the material in constant voltage gradients.

\section{Experimental procedure}

\section{1 Sample preparation}

Commercially available thickfilm substrates made of 96\% alumina (Rubalit 708S, CeramTec, Germany) were chosen as test material. Substrates with two different thicknesses were used for different tests. Short time tests with varying voltage ramp rates were performed on samples with a nominal thickness of 380 $\mu \mathrm{m}$. For short time tests with different electrodes and for withstand voltage tests, samples with a nominal thickness of $620 \mu \mathrm{m}$ were used. The as-delivered substrates were cut to square-shaped samples with $50 \mathrm{~mm}$ edge length. An average surface roughness of $R_{\mathrm{a}}=0.3 \mu \mathrm{m}$ with a standard deviation of $0.01 \mu \mathrm{m}$ was determined by measurements of 27 samples (three measurements per sample) using a tactile roughness tester (Hommel-Etamic W10, Jenoptik, Germany). Before testing or metallization, the samples were cleaned in an ultrasonic bath using a 1:1 mixture of ethanol and acetone and subsequently dried at $105{ }^{\circ} \mathrm{C}$ for $2 \mathrm{~h}$. One group of 56 samples was metallized by screen printing of a $25 \mathrm{~mm}$ diameter spherical palladium/silver electrode (DuPont 6134, DuPont U.K. Limited, UK) and firing at $850{ }^{\circ} \mathrm{C}$ for $10 \mathrm{~min}$.

\section{2 Dielectric strength testing}

A $35 \mathrm{kV}$ alternating voltage measuring system (WGBS 4.4/35-50 HPS, HIGHVOLT, Germany), operating at commercial frequency of $50 \mathrm{~Hz}$, was used for all measurements. Dielectric strength testing was performed according to ASTM D149 [23]. The thickness of each specimen was measured before testing using a micrometer screw. The sample to be tested was placed between two well aligned stainless steel cylinder electrodes in a custom-made sample holder. If not stated otherwise, a new pair of electrodes was used for each measurement. After carefully mounting the 
sample, the sample holder was placed in a bath of insulating oil (Diala S2 ZU, Shell). Short time tests were performed by increasing the voltage with a defined ramp until the current sensing element detected the dielectric breakdown. At dielectric breakdown, the voltage was shut off immediately by a circuit breaking device. The actual voltage value at breakdown was recorded. Dielectric strength was the quotient of breakdown voltage and sample thickness. Withstand voltage tests were performed by increasing the voltage by a defined ramp rate to a defined value. The voltage was held constant until breakthrough was detected. The withstand time at the voltage plateau was recorded.

To study the influence of the voltage ramp rate on dielectric strength, short time tests with voltage ramp rates of $0.5,1$, and $2 \mathrm{kV} / \mathrm{s}$ were performed. According to ASTM D149, a voltage ramp rate should be chosen that leads to dielectric breakthrough within $10-20 \mathrm{~s}$. Groups of 25 samples of $380 \mu \mathrm{m}$ thick substrates were tested with each ramp rate using cylinder electrodes with $6.4 \mathrm{~mm}$ diameter.

The influence of electrode configuration on dielectric strength was studied by four different electrode arrangements on $620 \mu \mathrm{m}$ thick samples. One group of 20 samples was tested using a new pair of $6.4 \mathrm{~mm}$ cylinder electrodes for each sample (Fig. 1(a)). A second group of 20 samples was tested using a new pair of $25 \mathrm{~mm}$ for each sample (Fig. 1(b)). The third group of 20 samples was tested using the same pair of $6.4 \mathrm{~mm}$ cylinder electrodes for the entire group. After each test, the electrodes were cleaned with ethanolsoaked tissue to remove adherent insulating oil. The fourth group consisted of 56 samples metallized with a $25 \mathrm{~mm}$ circular silver electrode. These samples were mounted on a sphere-on-plate sample holder (Fig. 1(c)). Therefore, a sample was placed on the stainless-steel a)

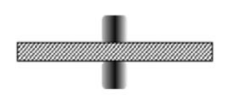

b)

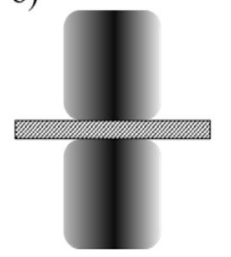

c)

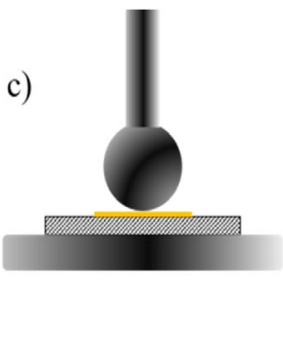

Fig. 1 Schematic drawings of electrode setups: (a) $6.4 \mathrm{~mm}$ cylinder electrodes on $50 \mathrm{~mm}$ sample, (b) $25 \mathrm{~mm}$ cylinder electrodes on $50 \mathrm{~mm}$ sample, (c) $50 \mathrm{~mm}$ sample with $25 \mathrm{~mm}$ thickfilm electrode and ball-on-sphere sample holder. plate and the stainless-steel sphere was placed in the center of the screen-printed electrode. The same plate and sphere were used for the entire group. With all four electrode configurations, short time tests with a voltage ramp rate of $1 \mathrm{kV} / \mathrm{s}$ were performed to determine the dielectric strength.

Withstand voltage tests were performed using $6.4 \mathrm{~mm}$ cylinder electrodes and a voltage ramp rate of $1 \mathrm{kV} / \mathrm{s}$. A group of ten $620 \mu \mathrm{m}$ thick samples was tested at $14 \mathrm{kV}$, which equals a voltage gradient of $23 \mathrm{kV} / \mathrm{mm}$ with respect to the sample thickness.

A second group of nine samples (thickness $620 \mu \mathrm{m}$ ) was tested at $12.4 \mathrm{kV}(20 \mathrm{kV} / \mathrm{mm})$. A time limit of $5 \mathrm{~h}$ was set for these measurements.

\section{3 Evaluation}

Cross-sections of several broken samples were prepared by cutting and polishing to the center of the breakdown channel. Images of the breakdown channels were taken after carbon vapor deposition using a scanning electron microscope (SEM, Gemini Supra 40, Zeiss, Germany) with secondary electron detector. For the statistical evaluation of the dielectric strength results, the software Origin 2018 (OriginLab Corporation, USA) was used. The level of significance was set to 0.05 for all statistical tests.

Dielectric strength values of a group of samples typically show a certain distribution. Two types of probability distributions have been considered in this study to describe the data: normal (or Gaussian) distribution and Weibull distribution. A normal distribution is characterized by a mean value $\bar{x}$ and a standard deviation $\sigma$. The probability density function is

$$
f(x)=\frac{1}{\sigma \sqrt{2 \pi}} \mathrm{e}^{\frac{(x-\bar{x})^{2}}{2 \sigma^{2}}}
$$

The Weibull distribution is commonly applied to describe the distribution of mechanical strength, time to failure, or even dielectric strength. It is characterized by a Weibull modulus $m$ and a scale parameter $\sigma_{0}$, in materials science often termed characteristic strength. The Weibull probability density function is

$$
f(x)=\frac{m}{\sigma_{0}}\left(\frac{x}{\sigma_{0}}\right)^{m-1} \mathrm{e}^{-\left(\frac{x}{\sigma_{0}}\right)^{m}}
$$

The density functions appear as lines if plotted in 
specific probability grids. Thus, graphing in probability grids is a convenient way to visualize if experimental data follows the respective distribution. Figures 4, 6, and 7 show the experimental data plotted in Weibull and normal probability grids as data points. The reference lines in the graphs show the ideal slope of the density functions with the characteristic parameters determined from the experimental data. Additionally, Kolmogorov-Smirnov test was used to test if the data is normally (or Gaussian) distributed.

\section{Results}

Disruptive discharge at breakdown leads to the formation of a breakdown channel in all tested specimens. Figure 2 shows a representative image of such a channel. Channel formation is accompanied by light and noise emission and characterized by material removal, melt formation, and cracking. The location of the breakdown is often, but not always, near the edge of the electrode. No obvious differences in the breakdown event and the resulting channel with respect to voltage ramp, electrode size, or withstand time are observed.

The results of dielectric strength tests with different voltage ramp rates are shown in Fig. 3. A normal distribution of the data cannot be rejected (KolmogorovSmirnov, $\alpha=0.05$ ). No clear trend regarding the influence of voltage ramp can be found. With increasing ramp rate, the mean values change from 31.8 to $31.1 \mathrm{kV} \cdot \mathrm{mm}^{-1}$ and further to $32.2 \mathrm{kV} \cdot \mathrm{mm}^{-1}$. The standard deviation is $<2 \mathrm{kV} \cdot \mathrm{mm}^{-1}$ for all three test conditions. One upper outlier is detected for 1 and $2 \cdot \mathrm{kV}^{-1}$. Although the absolute differences are small, the difference between

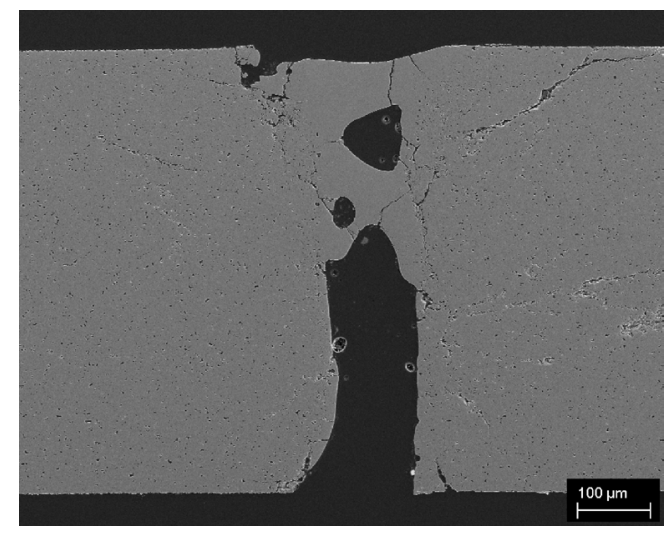

Fig. 2 Section of a channel formed by disruptive discharge in $\mathrm{Al}_{2} \mathrm{O}_{3}$ (SEM, SE-detector).
0.5 and $2 \mathrm{kV} \cdot \mathrm{s}^{-1}$, as well as the difference between 1 and $2 \mathrm{kV} \cdot \mathrm{s}^{-1}$ are statistically significant (two-sample $\mathrm{t}$-test, $\alpha=0.05$ ). The mean values for 0.5 and $1 \mathrm{kV} \cdot \mathrm{s}^{-1}$ are not significantly different. The time to failure is too long (22-28 s) for $0.5 \mathrm{kV} \cdot \mathrm{s}^{-1}$ and too short $(6-7 \mathrm{~s})$ for $2 \mathrm{kV} \cdot \mathrm{s}^{-1}$ regarding the specification the standard. At $1 \mathrm{kV} \cdot \mathrm{s}^{-1}$ breakdown occurs after $11-13 \mathrm{~s}$.

The Weibull plots of these data are shown in Fig. 4. The experimental data poorly fit the reference lines. With respect to the voltage ramps of $0.5,1$, and $2 \mathrm{kV} \cdot \mathrm{s}^{-1}$, the Weibull moduli are 17.0, 19.6, and 18.7. The characteristic dielectric strength at $63 \%$ failure probability is $32.7,31.9,34.0 \mathrm{kV} \cdot \mathrm{mm}^{-1}$, respectively.

Figure 5 shows the results of dielectric strength tests performed with different types of electrodes. Standard

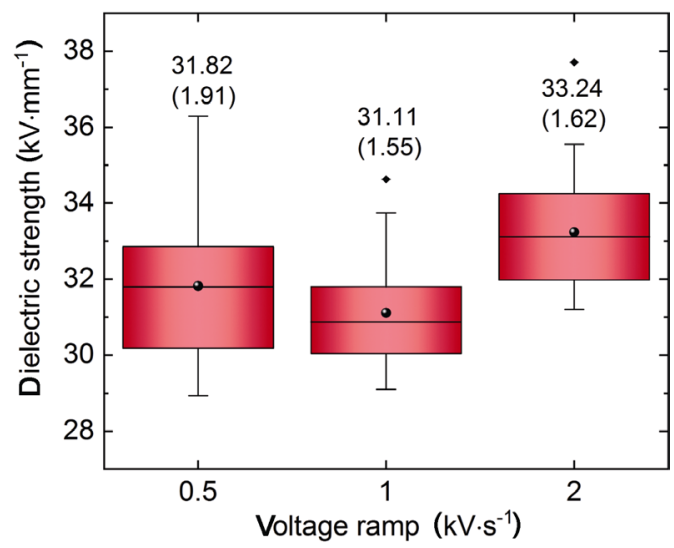

Fig. 3 Dielectric strength (AC) of $380 \mu$ m thick $\mathrm{Al}_{2} \mathrm{O}_{3}$ tested with different voltage ramp rates. Arithmetic mean values are drawn as black dot and written in the diagram, standard deviation in parentheses. Boxes show the median, $5 \%$, and $95 \%$ percentiles, and whiskers show minimum and maximum values. Outliers are drawn as black diamonds.

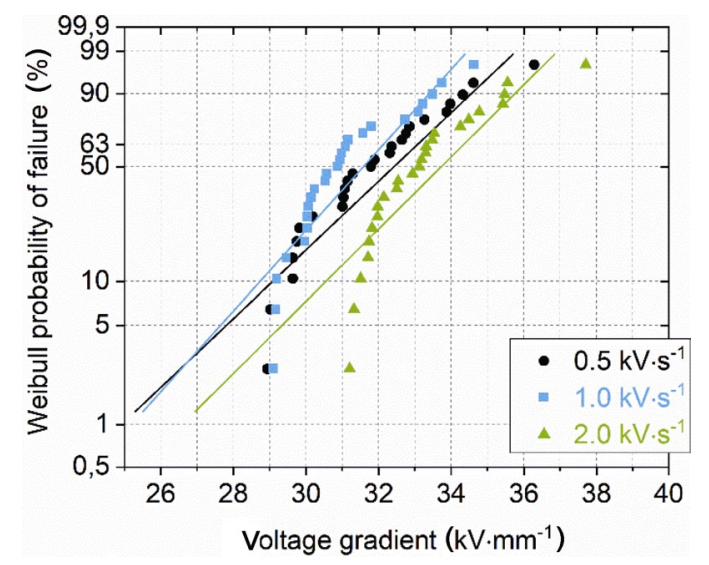

Fig. 4 Weibull probability grid plot of dielectric strength (AC) of $380 \mu \mathrm{m} \mathrm{Al}{ }_{2} \mathrm{O}_{3}$ for different voltage ramp rates. 


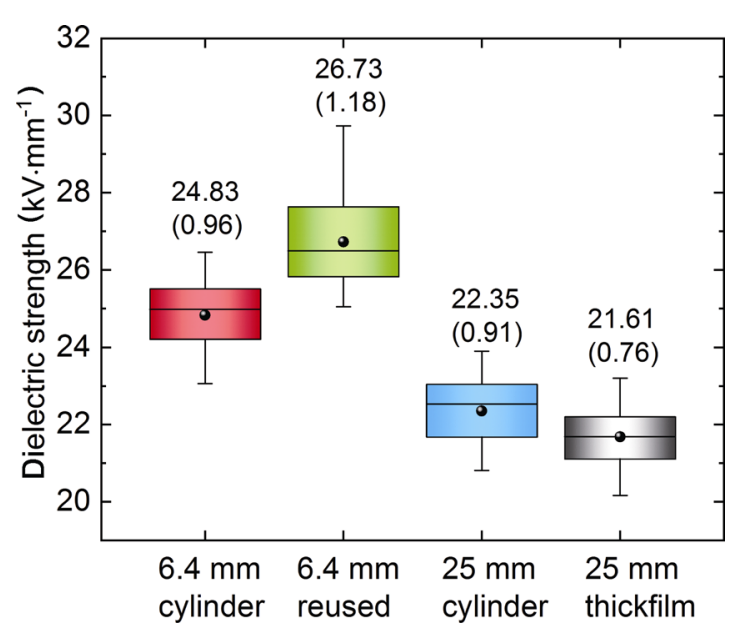

Fig. 5 Dielectric strength (AC) of $620 \mu \mathrm{m}$ thick $\mathrm{Al}_{2} \mathrm{O}_{3}$ measured with different electrodes. Arithmetic mean values are drawn as black dots and written in the diagram, standard deviation in parentheses. Boxes show the median, $5 \%$, and $95 \%$ percentiles, whiskers show minimum and maximum values.

deviations are similar and $<1.2 \mathrm{kV} \cdot \mathrm{mm}^{-1}$ for all test conditions. The mean values change with respect to the electrode setup. Normal distribution of the data cannot be rejected for all test conditions (KolmogorovSmirnov, $\alpha=0.05$ ). A normal probability plot of the data is shown in Fig. 6. Differences in mean values are significant for all comparisons (two-sample t-test, $\alpha=0.05$ ). Best practice testing, that is new electrodes for each test, results in a dielectric strength of 24.8 $\mathrm{kV} \cdot \mathrm{mm}^{-1}$ for $6.4 \mathrm{~mm}$ electrodes and $22.4 \mathrm{kV} \cdot \mathrm{mm}^{-1}$ for $25 \mathrm{~mm}$ electrodes, respectively. This is a $9.6 \%$ decrease of $2.4 \mathrm{kV} \cdot \mathrm{mm}^{-1}$ with respect to the smaller electrodes. Reusing the same pair of $6.4 \mathrm{~mm}$ electrodes results in an increase of the mean value of $1.9(7.6 \%)$ to $26.7 \mathrm{kV} \cdot \mathrm{mm}^{-1}$. Testing with $25 \mathrm{~mm}$ thickfilm electrodes results in $21.6 \mathrm{kV} \cdot \mathrm{mm}^{-1}$, which is $0.7 \mathrm{kV} \cdot \mathrm{mm}^{-1}(3.4 \%)$ lower than for $25 \mathrm{~mm}$ cylinder electrodes and $3.2 \mathrm{kV} \cdot \mathrm{mm}^{-1}(12.9 \%)$ lower than for best practice testing with $6.4 \mathrm{~mm}$ cylinders. Comparing reused $6.4 \mathrm{~mm}$ electrodes with printed $25 \mathrm{~mm}$ electrodes, a considerable difference of $5.1 \mathrm{kV} \cdot \mathrm{mm}^{-1}$ is observed, which corresponds to more than $22 \%$ of the total mean value.

The Weibull probability plot of dielectric strength data determined by short time tests with different electrode configurations is shown in Fig. 7. Weibull moduli differ between 21.4 for reused $6.4 \mathrm{~mm}$ electrodes and 31.7 for $25 \mathrm{~mm}$ thickfilm electrodes. Best practice testing results in Weibull moduli of 29.5

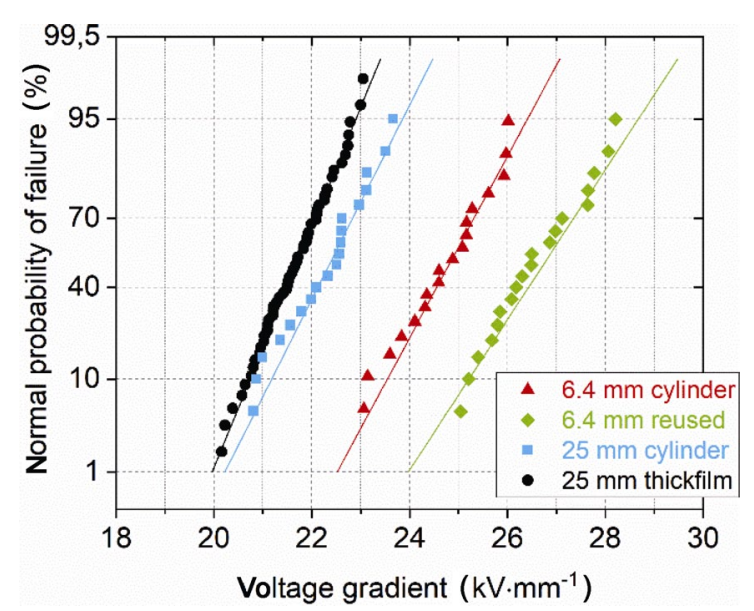

Fig. 6 Normal probability grid plot of dielectric strength (AC) of $620 \mu \mathrm{m} \mathrm{Al}_{2} \mathrm{O}_{3}$.

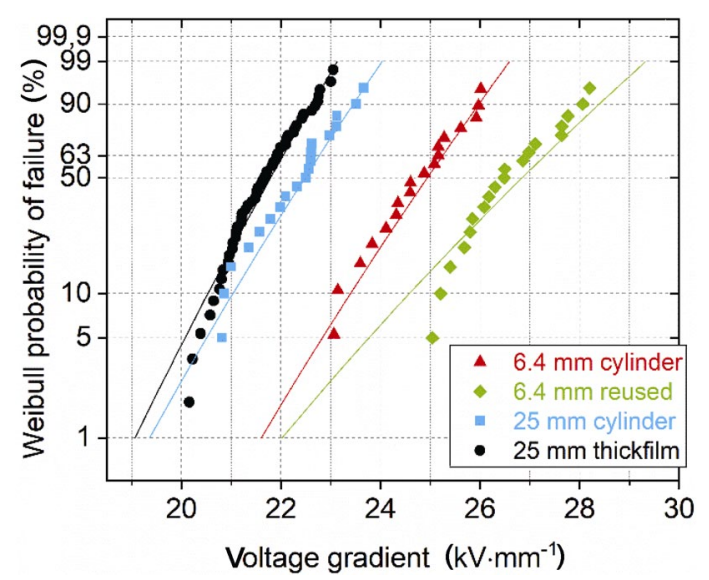

Fig. 7 Weibull probability grid plot of dielectric strength (AC) of $620 \mu \mathrm{m} \mathrm{Al}_{2} \mathrm{O}_{3}$.

for $6.4 \mathrm{~mm}$ cylinders and 28.3 for $25 \mathrm{~mm}$ cylinders. The characteristic dielectric strength at $63 \%$ failure probability is the highest for reused $6.4 \mathrm{~mm}$ cylinders $\left(27.2 \mathrm{kV} \cdot \mathrm{mm}^{-1}\right)$ and the lowest for the $25 \mathrm{~mm}$ thickfilm electrodes $\left(22.0 \mathrm{kV} \cdot \mathrm{mm}^{-1}\right)$. The difference amounts to $5.3 \mathrm{kV} \cdot \mathrm{mm}^{-1}$. The difference of characteristic dielectric strength determined with small $\left(25.2 \mathrm{kV} \cdot \mathrm{mm}^{-1}\right)$ and big electrodes $\left(22.8 \mathrm{kV} \cdot \mathrm{mm}^{-1}\right)$ amounts to $2.4 \mathrm{kV} \cdot \mathrm{mm}^{-1}$.

Two series of withstand voltage tests have been conducted. The results are shown in Fig. 8. A broad distribution of withstand time is observed. In a voltage gradient of $23 \mathrm{kV} \cdot \mathrm{mm}^{-1}$, the withstand time scatters between $7 \mathrm{~s}$ and $7 \mathrm{~min}(422 \mathrm{~s})$. Five samples $(50 \%)$ fail within $47 \mathrm{~s}$. Of the nine samples tested in the lower voltage gradient of $20 \mathrm{kV} \cdot \mathrm{mm}^{-1}$, three samples do not fail over a period of five hours. One sample fails already after $2.12 \mathrm{~min}$. Three of nine samples fail within $10 \mathrm{~min}$. 


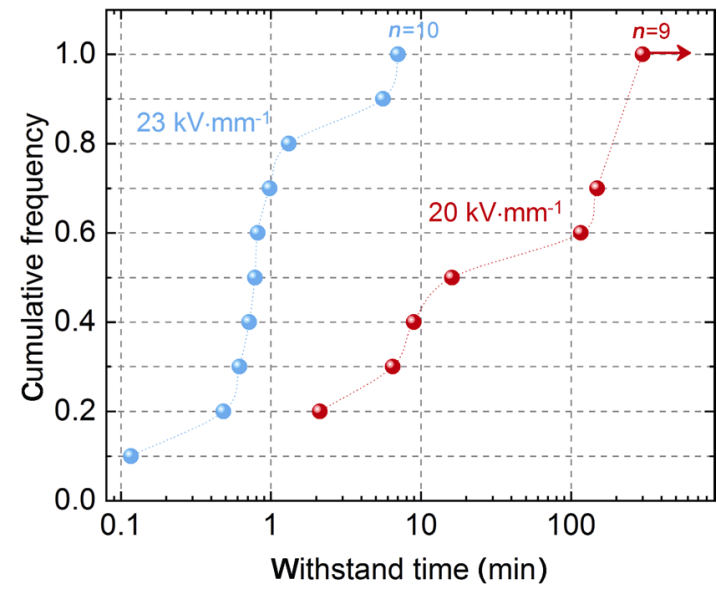

Fig. 8 Cumulative frequencies of withstand time of 620 $\mu \mathrm{m} \mathrm{Al}_{2} \mathrm{O}_{3}$ tested under different $\mathrm{AC}$ voltage gradients.

\section{Discussion}

Significantly different values of dielectric strength for the same material have been determined with respect to the different measurement conditions. The expectations regarding the basic effect of the parameters could be confirmed: thinner samples, smaller electrodes, and faster voltage ramp rates result in higher dielectric strength values. Voltage ramp shows only a minor influence in this study. But the bandwidth of ramp rates tested is rather small. In lab testing facilities, often slower ramp rates are used for characterization, which may affect the results substantially. For a better overview, all short time test results and the respective test conditions are summarized in Table 1. The highest dielectric strength measured in this study (33.24 $\mathrm{kV} \cdot \mathrm{mm}^{-1}$ ) is determined on $380 \mu \mathrm{m}$ thin samples using small $6.4 \mathrm{~mm}$ electrodes and a voltage ramp of $2 \mathrm{kV} \cdot \mathrm{s}^{-1}$. In contrast, measurements of $620 \mu \mathrm{m}$ thick samples using $25 \mathrm{~mm}$ thickfilm electrodes and a voltage

Table 1 Summary of all short time test conditions and results

\begin{tabular}{ccccccc}
\hline $\begin{array}{c}\text { Sample } \\
\text { thickness } \\
(\mu \mathrm{m})\end{array}$ & $\begin{array}{c}\text { Electrode } \\
\text { diamete } \\
(\mathrm{mm})\end{array}$ & $\begin{array}{c}\text { Electrode } \\
\text { condition }\end{array}$ & $\begin{array}{c}\text { Voltage } \\
\text { ramp rate } \\
\left(\mathrm{kV} \cdot \mathrm{s}^{-1}\right)\end{array}$ & $\begin{array}{c}\text { Number } \\
\text { of } \\
\text { samples }\end{array}$ & $\begin{array}{c}E_{\mathrm{D}} \\
\left(\mathrm{kV} \cdot \mathrm{mm}^{-1}\right)\end{array}$ & $\begin{array}{c}\text { Standard } \\
\text { deviation } \\
\left(\mathrm{kV} \cdot \mathrm{mm}^{-1}\right)\end{array}$ \\
\hline 380 & 6.4 & New & 0.5 & 25 & 31.82 & 1.91 \\
380 & 6.4 & New & 1.0 & 25 & 31.11 & 1.55 \\
380 & 6.4 & New & 2.0 & 25 & 33.24 & 1.62 \\
620 & 6.4 & New & 1.0 & 20 & 24.83 & 0.96 \\
620 & 6.4 & Reused & 1.0 & 20 & 26.73 & 1.18 \\
620 & 25 & New & 1.0 & 20 & 22.35 & 0.91 \\
620 & 25 & Thickfilm & 1.0 & 56 & 21.61 & 0.76 \\
\hline
\end{tabular}

ramp of $1 \mathrm{kV} \cdot \mathrm{s}^{-1}$ result in $21.61 \mathrm{kV} \cdot \mathrm{mm}^{-1}$. The difference amounts to $11.63 \mathrm{kV} \cdot \mathrm{mm}^{-1}$, which is a $53.8 \%$ deviation related to the smaller value and a $34.9 \%$ deviation related to the larger value, respectively. The major contribution to the difference in this comparison is the sample thickness. Comparing the two substrate types measured with the same setup $\left(6.4 \mathrm{~mm}\right.$ electrodes and $\left.1 \mathrm{kV} \cdot \mathrm{s}^{-1}\right)$, a difference of $6.28 \mathrm{kV} \cdot \mathrm{mm}^{-1}$ is found. This is already a relative difference of $20.2 \%$ related to the large value, and $25.3 \%$ related to the small value, respectively. As described in the introduction, dielectric strength is indirectly proportional to the square root of the sample thickness $[6,8]$. Based on this relationship, a normalized dielectric strength $E_{\mathrm{d}, \mathrm{n}}$ with respect to a normalized thickness $t_{\mathrm{n}}$ can be calculated according to Eq. (3) $[11,17]$, where $U_{\mathrm{b}}$ is the breakdown voltage and $t$ is the actual thickness of the sample.

$$
E_{\mathrm{d}, \mathrm{n}}=\frac{U_{\mathrm{b}}}{t} \cdot \sqrt{\frac{t}{t_{\mathrm{n}}}}
$$

The normalized dielectric strength of $380 \mu \mathrm{m}$ substrates $\left(6.4 \mathrm{~mm}\right.$ electrodes and $\left.1 \mathrm{kV} \cdot \mathrm{s}^{-1}\right)$ with $t_{\mathrm{n}}=$ $620 \mu \mathrm{m}$ amounts to $24.4 \mathrm{kV} \cdot \mathrm{mm}^{-1}\left( \pm 1.2 \mathrm{kV} \cdot \mathrm{mm}^{-1}\right)$. This is in very good agreement with $24.8 \mathrm{kV} \cdot \mathrm{mm}^{-1}$ $\left( \pm 0.96 \mathrm{kV} \cdot \mathrm{mm}^{-1}\right)$ for real $620 \mu \mathrm{m}$ substrates tested with the same setup. The difference of these mean values is not statistically significant (two-sample t-test, $\alpha=0.05$ ).

The Weibull plot for different electrode configurations (Fig. 7) shows significantly reduced characteristic dielectric strength for larger electrodes. This result is in accordance with the work of Neusel et al. [8], who predicted an increasing failure probability for breakdown with increasing electrode area based on rearrangements of the basic equations of the Weibull distribution. The increase of characteristic dielectric strength by reusing the electrodes is an unexpected result. The standard recommends substituting the electrodes if burn-off is visible [23]. In our test, disruptive discharge during breakdown leads to the formation of pits at the electrode surface, mostly located near the electrode edge. These pits appear as innocuous black spots to the naked eyes. But optical profilometry of used electrodes shows removal of material at these locations. Interestingly, discharge never happens twice at the same location on the electrode surface. Still, the deterioration of electrode surface quality due to disruptive discharge causes significantly higher measurement results (Fig. 5). 
Moreover, dielectric strength values appear to increase with increasing number of tests. In the group of 20 samples, the mean value of the first ten samples $\left(26.2 \pm 0.9 \mathrm{kV} \cdot \mathrm{mm}^{-1}\right)$ is significantly lower than the mean value of the last ten samples $\left(27.3 \pm 1.2 \mathrm{kV} \cdot \mathrm{mm}^{-1}\right)$ (two-sample t-test, $\alpha=0.05$ ). The outer diameter of the electrode remains unchanged during continuous usage. Thus, a reduction of electrode area is probably not the reason for this effect. Differences in electric field distribution due to degrading surface smoothness of the electrode and contamination in the surface pits may be the cause for successively increasing results.

Testing with thickfilm electrodes is faster and more cost-effective than testing with constantly replaced stainless-steel cylinders, especially for large numbers of samples. This study shows that only a minor difference in Weibull modulus and characteristic strength is found compared to cylinder electrodes of the respective diameter, although the difference in mean values is significant. The similarity of results determined with cylinder and thickfilm electrodes is interesting because of the location of the discharges. The edge of the $25 \mathrm{~mm}$ cylinders is rounded to a radius of $3.2 \mathrm{~mm}$ and discharge occurs often but not always near the edge. On all 56 thickfilm samples, the discharge occurs at the sharp edge of the printed electrode. One can assume that distribution and concentration of the electric field is different at the different electrode edges (printed and cylinder), and more inhomogeneous at thickfilm electrodes. This would be a clear disadvantage of printed electrodes. Still, difference in the results is smaller compared to the difference between new and reused $6.4 \mathrm{~mm}$ electrodes. Testing of hemispherically recessed and metallized samples is possible to eliminate this edge effect. But the sample preparation is intricate. More studies are necessary to validate the suitability of flat, thickfilm metallized samples for dielectric strength testing.

The voltage gradients for the withstand tests were chosen based on the results of the short time tests with the respective setup $\left(6.4 \mathrm{~mm}\right.$ electrodes and $\left.1 \mathrm{kV} \cdot \mathrm{s}^{-1}\right)$. A voltage gradient of $23 \mathrm{kV} \cdot \mathrm{mm}^{-1}$ equals the smallest dielectric strength measured in the short time test. The probability of failure at $23 \mathrm{kV} \cdot \mathrm{mm}^{-1}$ is $\sim 5 \%$. Still, $70 \%$ of the samples failed within one minute and no sample lasted longer than 10 minutes. Apparently, dielectric strength and failure probabilities cannot easily be transferred from short time tests to withstand tests. This hypothesis is substantiated by the results of the
$20 \mathrm{kV} \cdot \mathrm{mm}^{-1}$ tests. Although the failure probability from short time tests is virtually zero, roughly every second sample fails within several minutes. The mean dielectric strength and Weibull distribution from short time tests of 20 samples suggest a safe use of the substrate at $20 \mathrm{kV} \cdot \mathrm{mm}^{-1}$, but the withstand tests show a broad distribution of withstand time. A Weibull evaluation of the withstand time results in Weibull moduli of 0.9 for $23 \mathrm{kV} \cdot \mathrm{mm}^{-1}$ and 0.7 for $20 \mathrm{kV} \cdot \mathrm{mm}^{-1}$. Please note that nine and ten samples are too few for a reliable Weibull evaluation. Still, these low moduli are contrary to the comparatively high Weibull moduli determined in the short time tests.

Frequent depolarization and partial discharge at pores and defects during $\mathrm{AC}$ testing cause an increasing damage of the material throughout the test. Thus, breakdown strength is lower for slower ramp rates and failure probability is higher at lower voltage levels in withstand tests than in short time tests. Apparently, time dependent progressive degradation is more sensitive to microstructural defects than short time failure at peak voltage. The large scatter of withstand time then reflects the uneven distribution of defect size and density in the different samples. This implies that withstand testing at intermediate voltage is better suited for studying microstructural influence on dielectric breakdown and evaluating homogeneity and reliability of material batches.

\section{Summary and conclusions}

Dielectric strength values are significantly affected by the sample thickness, voltage ramp rate, electrode size, and electrode conditioning used for testing. The $1 / \sqrt{t}$ dependence of dielectric strength is confirmed in this study. Thinner samples, smaller electrodes, and faster voltage ramps lead to higher breakdown voltages and thus higher dielectric strength values. Although these issues are well known for a long time, quantification of these effects is hardly discussed in literature and, even more remarkable, important details of the testing procedure are missing in many current publications. A meaningful comparison of results from different sources is therefore often not possible. In this study, variations of the testing procedure resulted in differences of dielectric strength of $>50 \%$ for the exact same material. Changing the electrode size and conditioning resulted in deviations of $22 \%$ from the overall mean 
value of samples of the same material and geometry. It appears obvious that it is not sensible to provide a value of dielectric strength for a given material without proper description of the measurement. To avoid uncertainties regarding the influence of degrading electrode surface quality on the measurement result, the use of new electrodes for each test is recommendable. Moreover, we show a stark contrast in Weibull moduli determined in standardized short time tests (modulus $\approx$ 30 ) and withstand voltage tests (modulus $<1$ ) using the same testing setup and voltage levels. Consequently, safe operation voltages determined in short time tests should not be transferred to continuous operation. These results give cause for the development of new testing strategies to reliably, comprehensively, and comparably characterize the dielectric strength of ceramic materials.

\section{Acknowledgements}

The author likes to thank W. Guether and J. Biberstein for performing the numerous measurements and S. Benemann (BAM Division 6.1) for SEM analysis.

\section{References}

[1] Gerson R, Marshall TC. Dielectric breakdown of porous ceramics. J Appl Phys 1959, 30: 1650-1653.

[2] Owate IO, Freer R. AC breakdown characteristics of ceramic materials. J Appl Phys 1992, 72: 2418-2422.

[3] Kishimoto A, Koumoto K, Yanagida H. Mechanical and dielectric failure of $\mathrm{BaTiO}_{3}$ ceramics. J Mater Sci 1989, 24: 698-702.

[4] Kishimoto A, Koumoto K, Yanagida H. Comparison of mechanical and dielectric strength distributions for variously surface-finished titanium dioxide ceramics. $J \mathrm{Am}$ Ceram Soc 1989, 72: 1373-1376.

[5] Young AL, Hilmas GE, Zhang SC, et al. Mechanical vs. electrical failure mechanisms in high voltage, high energy density multilayer ceramic capacitors. J Mater Sci 2007, 42: 5613-5619.

[6] Malec D, Bley V, Talbi F, et al. Contribution to the understanding of the relationship between mechanical and dielectric strengths of alumina. J Eur Ceram Soc 2010, 30: 3117-3123.

[7] Haddour L, Mesrati N, Goeuriot D, et al. Relationships between microstructure, mechanical and dielectric properties of different alumina materials. J Eur Ceram Soc 2009, 29: 2747-2756.

[8] Neusel C, Jelitto H, Schmidt D, et al. Thicknessdependence of the breakdown strength: Analysis of the dielectric and mechanical failure. J Eur Ceram Soc 2015,
35: 113-123.

[9] Hoshina T, Yamazaki M, Takeda H, et al. Dielectric breakdown mechanism of perovskite-structured ceramics. Additional Conferences (Device Packaging, HiTEC, HiTEN, \& CICMT) 2015, 2015: 000116-000120.

[10] Touzin M, Goeuriot D, Fitting HJ, et al. Relationships between dielectric breakdown resistance and charge transport in alumina materials-Effects of the microstructure. J Eur Ceram Soc 2007, 27: 1193-1197.

[11] Liebault J, Vallayer J, Goeuriot D, et al. How the trapping of charges can explain the dielectric breakdown performance of alumina ceramics. J Eur Ceram Soc 2001, 21: 389-397.

[12] Suo Z. Models for breakdown-resistant dielectric and ferroelectric ceramics. J Mech Phys Solids 1993, 41: 1155-1176.

[13] Schneider GA. A Griffith type energy release rate model for dielectric breakdown under space charge limited conductivity. J Mech Phys Solids 2013, 61: 78-90.

[14] Neusel C, Jelitto H, Schneider GA. Electrical conduction mechanism in bulk ceramic insulators at high voltages until dielectric breakdown. J Appl Phys 2015, 117: 154902.

[15] Neusel C, Schneider GA. Size-dependence of the dielectric breakdown strength from nano- to millimeter scale. J Mech Phys Solids 2014, 63: 201-213.

[16] Fischer PK, Schneider GA. Dielectric breakdown toughness from filament induced dielectric breakdown in borosilicate glass. J Eur Ceram Soc 2018, 38: 4476-4482.

[17] Touzin M, Goeuriot D, Guerret-Piécourt C, et al. Alumina based ceramics for high-voltage insulation. J Eur Ceram Soc 2010, 30: 805-817.

[18] Fuertes V, Cabrera MJ, Seores J, et al. Hierarchical micro-nanostructured albite-based glass-ceramic for high dielectric strength insulators. J Eur Ceram Soc 2018, 38: 2759-2766.

[19] Ye XY, Li YM, Bian JJ. Dielectric and energy storage properties of Mn-doped $\mathrm{Ba}_{0.3} \mathrm{Sr}_{0.475} \mathrm{La}_{0.12} \mathrm{Ce}_{0.03} \mathrm{TiO}_{3}$ dielectric ceramics. J Eur Ceram Soc 2017, 37: 107-114.

[20] Yuan QB, Cui J, Wang YF, et al. Significant enhancement in breakdown strength and energy density of the $\mathrm{BaTiO}_{3} /$ $\mathrm{BaTiO}_{3} @ \mathrm{SiO}_{2}$ layered ceramics with strong interface blocking effect. J Eur Ceram Soc 2017, 37: 4645-4652.

[21] Luo BC, Wang XH, Tian EK, et al. Enhanced energystorage density and high efficiency of lead-free $\mathrm{CaTiO}_{3}$ $\mathrm{BiScO}_{3}$ linear dielectric ceramics. ACS Appl Mater Interfaces 2017, 9: 19963-19972.

[22] Lei W, Yan YY, Wang XH, et al. Improving the breakdown strength of $\left(\mathrm{Mg}_{0.9} \mathrm{Zn}_{0.1}\right)_{2}\left(\mathrm{Ti}_{1-x} \mathrm{Mn}_{x}\right) \mathrm{O}_{4}$ ceramics with low dielectric loss. Ceram Int 2015, 41: 521-525.

[23] ASTM D149-09(2013). Standard test method for dielectric breakdown voltage and dielectric strength of solid electrical insulating materials at commercial power frequencies. ASTM International, West Conshohocken, PA, 2013.

Open Access This article is licensed under a Creative 
Commons Attribution 4.0 International License, which permits use, sharing, adaptation, distribution and reproduction in any medium or format, as long as you give appropriate credit to the original author(s) and the source, provide a link to the Creative Commons licence, and indicate if changes were made.

The images or other third party material in this article are included in the article's Creative Commons licence, unless indicated otherwise in a credit line to the material. If material is not included in the article's Creative Commons licence and your intended use is not permitted by statutory regulation or exceeds the permitted use, you will need to obtain permission directly from the copyright holder.

To view a copy of this licence, visit http://creativecommons. org/licenses/by/4.0/. 